\title{
When multidisciplinary surgical trans-orbital approaches should be considered to reach the skull base
}

\author{
Ruolo degli approcci chirurgici multidisciplinari trans-orbitari nella gestione \\ della patologia del basicranio \\ lacopo Dallan ${ }^{1}$, Lodovica Cristofani-Mencacci ${ }^{1}$, Giacomo Fiacchini ${ }^{1}$, Michele Caniglia², Stefano Sellari-Franceschini' \\ Stefano Berrettini ${ }^{1}$ \\ ${ }_{1}^{1}$ Otolaryngology Unit, Department of Surgical, Medical, Molecular Pathology and Emergency Medicine, University Hospital of Pisa, \\ Italy; ${ }^{2}$ Department of Neurosurgery, University Hospital of Pisa, Italy
}

\begin{abstract}
SUMMARY
The transorbital approaches are a group of surgical procedures performed passing through the orbital spaces and aimed to reach deeper areas. This kind of surgery has been proved to be safe and effective in the management of selected lesions of the anterior, middle and infratemporal fossa. The aim of the present study is to perform a review of the literature, in order to draw the reader's attention on the main features of this kind of surgery, focusing on the anatomical background and the surgical setting; we will also summary the current indications and contraindications to this approach and find out the related complications and the possible alternatives. Even if we consider the transorbital approach as a promising route to the skull base, we underline that there is no better approach over another and the choice must always consider several elements. Furthermore, as for every skull base procedure, a multidisciplinary management is strongly advisable.
\end{abstract}

KEY WORDS: skull base, surgical procedures, orbit, endoscopy

\section{RIASSUNTO}

Sotto il termine "chirurgia trans-orbitaria" viene attualmente indicato un gruppo di procedure chirurgiche volte a raggiungere la base cranica, sfruttando la finestra orbitaria. Questo tipo di chirurgia si è dimostrata sicura ed efficace per la gestione di patologie selezionate della fossa cranica anteriore, della media e della fossa infratemporale. L'obiettivo di questo lavoro è quello di effettuare una revisione della letteratura, con lo scopo di veicolare l'attenzione del lettore su quelle che sono le principali caratteristiche di questo tipo di chirurgia, concentrandosi in particolare sul necessario background anatomico e sul setting operatorio richiesto; riassumeremo le attuali indicazioni e controindicazioni ed evidenzieremo le possibili complicanze associate a tale chirurgia e le eventuali alternative da intraprendere. Pur reputando che questa chirurgia sia molto promettente nella gestione di alcune patologie del basicranio, vogliamo tuttavia sottolineare come non esista mai un approccio chirurgico migliore di un altro in termini assoluti, e che la scelta finale debba essere sempre il frutto di considerazioni che valutano molteplici elementi. In ultimo, si vuole sottolineare che, come in altre procedure sul basicranio, i migliori risultati si ottengono con una gestione multidisciplinare.

PAROLE CHIAVE: base cranica, procedure chirurgiche, orbita, endoscopia

\section{Introduction}

Generally speaking, with the term "transorbital approaches" we consider a group of surgical procedures performed passing through the orbital spaces aimed to reach deeper areas. As a matter of fact, transorbital endoscopic-
Received: October 24, 2020

Accepted: January 16, 2021

Correspondence

Lodovica Cristofani-Mencacci

Otolaryngology Unit, Azienda Ospedaliero-Universitaria Pisana,

via Paradisa 2, 56124 Pisa, Italy

Tel. +39050997502

E-mail: lodovicacristofani@yahoo.it

Funding

None.

Conflict of interest

The Authors declare no conflict of interest.

How to cite this article: Dallan I, CristofaniMencacci L, Fiacchini G, et al. When multidisciplinary surgical trans-orbital approaches should be considered to reach the skull base. Acta Otorhinolaryngol Ital 2021;41(SUPPL.1):S59-S66. https://doi.org/10.14639/0392-100X-suppl.1-41-2021-06

() Società Italiana di Otorinolaringoiatria e Chirurgia Cervico-Facciale

\section{(c) (1) $(2)$}

This is an open access article distributed in accordance with the CC-BY-NC-ND (Creative Commons Attribution-NonCommercial-NoDerivatives 4.0 International) license. The article can be used by giving appropriate credit and mentioning the license, but only for non-commercial purposes and only in the original version. For further information: https:// creativecommons.org/licenses/by-nc-nd/4.0/deed.en 
assisted surgery is one of the most recent, fascinating and promising areas in skull base surgery. Its development should be considered as a natural step of the progression of the minimally invasive surgical approaches to the skull base. Transnasal endoscopic-assisted approaches, although incredibly evolved, have their own limits. Probably the two most important are: 1) the frequent need of angled endoscope and cross-planar technique and instruments to visualize and manage the surgical target; 2) the nasal corridor to the skull base becomes progressively constricted as the target is reached, especially in its lateral aspect. Furthermore, transnasal endoscopic approaches necessitate placement of the endoscope and instruments in a similar vector with minimal offset angle ${ }^{1}$. Based on these grounds, it came naturally to think of the orbit not only as a possible site of pathology but also as a corridor to deeper areas. Thanks to the innovative work of Kris Moe, this idea turned into reality ${ }^{2}$. This kind of surgery, named TONES (TransOrbital Neuro-Endoscopic Surgery) has been proved to be safe, and from the very initial experience several groups around the world have started to add their own data to this topic. Among the main advantages of TONES we include a shorter period of hospitalization, rapid recovery, very good cosmetic outcomes and reduced, if not absent, morbidity related to brain retraction ${ }^{2}$. More interestingly, this kind of approach has been successfully combined with other surgical procedures in order to offer multiple entry windows, overcoming the own limits of each of them, giving rise to a "multiportal" procedure. The golden rule of "not being dogmatic" is leading worldwide surgeons to introduce variations to the actually known solutions, always with the intent to improve results and minimize complications and sequelae. The aim of this manuscript is to perform a review of the literature, in order to investigate how this new transorbital approach could improve the skull base surgery. We will, therefore, highlight the characteristics that may be useful to clinician in the choice of the best approach for the patient, in a personalized view of the surgical practice. In this respect, although several incisions and approaches have been described and proposed ${ }^{1,3}$, in this chapter we will focus mainly on the superior eyelid endoscopic-assisted approach exploring the following items:

- anatomical background and surgical considerations;

- surgical instrumentation and setting (multidisciplinary management);

- current indications and contraindications;

- possible alternatives;

- complications;

- case examples.

Other transorbital approaches will not be discussed in this paper and we advice to refer to dedicated literature.

\section{Anatomical background and surgical considerations}

The superior eyelid, viewed from an anterior to posterior direction, is formed by two lamellae: an anterior lamella, consisting of skin and the orbicularis oculi muscle, a posterior lamella, consisting of Muller's palpebral muscle and levator aponeurosis. The orbital septum, in the upper part of the eyelid, is located between these two lamellae. The orbital septum is in continuity with the periorbita and the periosteum of the external cranial surface and it is a membranous sheet. The superior septum originates from the orbital rim at the arcus marginalis. Supero-medially, it is pierced by vessels and nerves. It is located medially behind the medial palpebral ligament and laterally it is located anteriorly to the lateral palpebral ligament. It attaches itself to Muller's muscle and the superior tarsus inferiorly, ending in the pre-tarsal skin. The upper eyelid is supported by the upper tarsal plate, which forms with its lateral and medial canthal tendons the tarso-ligamentous sling. The levator palpebrae and its aponeurosis form the superior eyelid retractor system, which passes inferiorly from the Whitnall's ligament to reach the tarsal plate and the pretarsal palpebral skin. Anatomically speaking Whitnall's ligament is a condensation of fascial covers around the levator palpebrae superioris muscle. As for the aponeurosis of the levator, its lateral horn is inserted on the Whitnall tubercle, while the medial horn is inserted on the posterior lacrimal crest. Muller's sympathetic muscle should be considered as an accessory tendon of the levator palpebrae, in the context of the upper eyelid. Along the anterior surface of the upper tarsus runs the marginal arterial arcade, mainly from the medial palpebral and lacrimal arteries. This means that the blood supply for the superior eyelid comes mainly from the ophthalmic artery. Lesser contribution comes from the infraorbital, temporal, transverse facial and angular arteries. At the level of the superolateral aspect of the orbital rim, the upper lobe of the lacrimal gland can be appreciated just behind the orbital septum. It lies above the lateral extension of the levator palpebrae fascial system. The lacrimal gland is divided into two portions: an orbital (or upper) portion that is lodged in the lacrimal fossa (frontal bone) and a palpebral portion that extends through the lateral horn of the levator aponeurosis into the supero-lateral fornix (it can be seen shining through the conjunctival layer). The upper and lower lateral tarsal tendons form the lateral canthal tendon. It inserts into the periorbita overlying the Whitnall's lateral tubercle. In the medial canthal tendon we can identify two heads, superficial and deep. The superficial head attaches anteriorly to the lacrimal fossa and the frontal process of the maxillary bone and it's thicker. The deep head attaches 
to the posterior lacrimal crest and it's thinner. The posterior limb of the medial canthal tendon gives the medial component of the orbital septum.

From an anatomo-surgical point of view, once the orbital rim is reached and skeletonized as needed, we then proceed with a careful sub-periosteal dissection until the lateral aspects of the superior (SOF) and inferior orbital fissures (IOF) are identified and adequately exposed. We strongly advice to perform a careful dissection, sparing the integrity of the periorbita (in order to avoid fat prolapse into the surgical field). During this dissection several bridging vessels can be identified; they must be coagulated and cut to avoid annoying bleeding during the procedure. In $50-60 \%$ of subjects the cranio-orbital foramen (Hyrthl's foramen) can be found; it is close to the superior orbital fissure and transmits usually the recurrent meningeal artery (also named meningolacrimal branch). As anatomical variation, this vessel can pass through the SOF. In transorbital "corridor" surgery, like the one discussed in this paper, when the periorbita is exposed it should be spared in order to create the "pocket room" for the instrumentations. As possible targets, in such an approach, we can identify the anterior and middle cranial fossa and even the infratemporal fossa (Fig. 1). Regardless the target, the first surgical step is to expose completely the inner surface of the temporalis muscle. By doing this, the room for work is enlarged and an increased surgical freedom for the intruments is gained. When dealing with a "middle cranial fossa approach" the orbital part of the

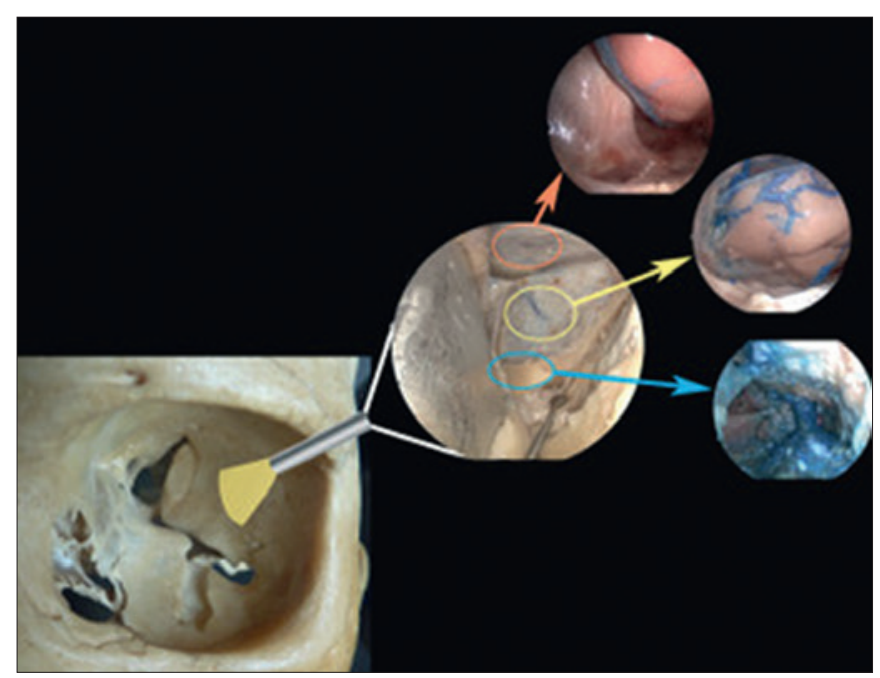

Figure 1. Multipanel figure showing the transorbital endoscopic-assisted approach to the skull base. The orange circle shows the position of the anterior cranial fossa (ACF); the orange narrow its content, the frontal lobe. The yellow circle shows the position of the middle cranial fossa (MCF); the yellow narrow the temporal lobe, which is behind the dura of the MCF. The light blue circle shows the position of the infratemporal fossa (ITF); the light blue narrows the content of the upper part of the ITF. greater wing of the sphenoid has to be completely removed to reach the dura mater of the anterior part of the temporal lobe. According to the target of surgery, the approach can be partially extended to the lesser wing of the sphenoid and toward the anterior clinoid process. If necessary, the frontal bone can be partially resected, and if an intradural work has been planned, the spheno-parietal sinus is advisable to be identified and managed. In case of intracranial approaches, the dura is opened and the anterior part of the temporal lobe of the brain is reached, as well as the lateral wall of the cavernous sinus. In more extended approach, once the lesser wing of the sphenoid and partially the frontal bone have been removed, the most medial part of the sylvian fissure and its content can be visualized.

If the meningo-orbital band is split, an interdural way to the lateral wall of the cavernous sinus and Meckel's cave is reached. This is not a proper intradural approach because it spares the integrity of the dura propria and avoids to expose the brain parenchima; anyway it allows a direct and efficent way to reach the Meckel's cave and the anterior petrosal area. If the lesion is located below the middle cranial fossa or in the upper infratemporal fossa area, an inferior extension of the "middle cranial fossa approach" can be performed removing the floor of the MCF thus exposing the upper aspect of the infra-temporal fossa content.

In an "anterior cranial fossa approach", the orbital part of the frontal bone is removed, along with a part of the lesser sphenoid wing, to perform a craniectomy. The greater wing of the sphenoid is normally only partially resected. Then the dura is exposed and opened if the procedure requires it. Intracranial work follows as necessary.

\section{Surgical instrumentations and setting}

Patient position is the same as for any standard endoscopic-assisted skull-base procedure. For extradural approaches we generally do not fix the head of the patient, while the head is normally fixed if intracranial dissection is anticipated. Anyway, the head position may be changed during surgery, thus allowing different angles of attack to the surgical target. It is strongly advisable that the operating room be set to allow a double screen vision and neuronavigation. We would like to emphatize the concept that this kind of surgery can be performed endoscopically and/or microscopically, or better yet in a combined blended solution.

In our experience, we never fix the endoscope in a holder, but it could be probably useful in some instances, as demonstrated by other groups. These procedures are usually performed via a 3-4 hands technique (Fig. 2). In transpalpebral procedures, the role of a third surgeon helping in creating adequate space for working is of paramount importance. In 


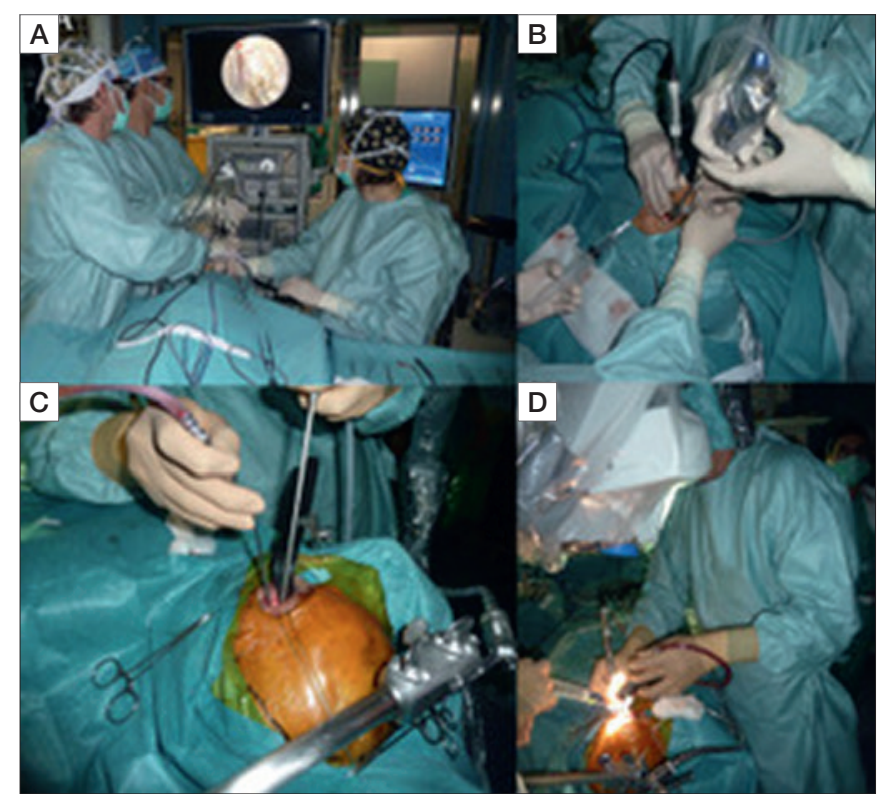

Figure 2. External intraoperative views of the surgical area in endoscopicassisted superior eyelid approaches. In $\mathbf{A}$ and $\mathbf{B}$ the surgical team is composed of 3 surgeons: the second surgeon holds the endoscope, the first surgeon is free to use both hands; the third surgeon create a wide surgical window. In D a combined endoscopic and microscopic-assisted procedure.

combined multiportal approaches, a good versatility of the surgical team is required. In this respect we would like to strongly underline the extreme importance of a multidisciplinary evaluation and management. The close collaboration with the neurosurgeon, opthalmoplastic surgeon, but also maxillofacial and interventional radiologist and radiotherapist is the key for the success. In other words we want to stress the concept that this kind of surgery should not be considered a "one-man show" but rather the field where different competences share their own experience and skill in a dynamic and harmonic fashion.

Regarding instrumentations, we can advice the use of typical neuroendoscopic instrumentation. A high-speed drill or eventually piezo-electric tool can be used for bony work. Also ultrasonic bone aspirators have been used for this purpose and showed their potential in selected cases.

\section{Current indications and contraindications}

Endoscopic transorbital approaches, although at their dawn, showed to be feasible and safe as a minimally invasive and minimally disruptive surgery ${ }^{4}$, able to provide direct access to deeper lateral areas of the facial skeleton and skull base. Transorbital procedures may be performed in case of disease involving the orbit itself or structures adjacent to the orbit, such as the paranasal sinuses, the infratemporal fossa, and the anterior and middle cranial base.
The choice of a transorbital endoscopic approach over transnasal or open transcranial pathways implies different considerations:

- the surgical team's preference and expertise;

- a good interdisciplinary cooperation among otolaryngologist, orbital surgeon and neurosurgeon;

- the biological behaviour of the lesion and the possibility to gain direct access to it with adequate surgical freedom;

- the chance to completely control the surgical field and any possible intraoperative complications ${ }^{5}$.

Among the current indications of a superior eyelid approach we can describe selected:

- spheno-orbital meningiomas;

- Meckel's cave schwannoma;

- laterally-located anterior cranial fossa meningioma;

- lesions within the lateral recess of the frontal sinus;

- laterally-located epidural abscesses;

- vascular and lymphatic malformations;

- skull base defects (mainly located in the lateral recess of the sphenoid sinus);

- other lesions of the Meckel's cave of the anterior petrous apex region;

- huge mucoceles of the orbit and cranial cavity (in combination with transnasal approach).

The transorbital endoscopic surgery, by means the superior, lateral and supero-lateral approaches (mainly performed via a superior eyelid approach), may be used in case of diseases involving the anterior cranial fossa, providing good access and visualization. Furthermore, the opening of the orbital roof in the floor of the frontal sinus allows reaching lateral lesions of the frontal sinus, difficult to access with transnasal surgery such as inverted papilloma and mucoceles ${ }^{6}$. At the same time, this kind of surgery allows working angles more favorable to expose the anterior skull base, preserving the paranasal system and physiology when possible. Literature on the topic mainly describes case reports and small case series, and one of the largest experiences of pure TONES is described by Ramakrishna and Moe in 2016, with 45 TONES procedures directed to the skull base ${ }^{4}$.

Among clinical indications to perform transorbital surgery for ACF, Authors report CSF leaks; repairs of cranial base fractures; selected tumours and optic nerve decompressions; meningoencephaloceles; inflammatory conditions and sinogenic infectious complications involving the anterior cranial fossa ${ }^{2,4,7}$. In all such cases the transorbital endoscopic surgery represented a viable technique for lesions difficult-to-reach with other pathways or an additional tool to gain the greater access to such challenging diseases ${ }^{8}$. One of the current main fields of interest using TONES is 
related to the management of disease within the middle cranial fossa. Skull base lesions of this area are traditionally challenging to be approached, because of the anatomical complexity of this region and the presence of noble neurovascular structures, such as the Internal Carotid Artery (ICA), several cranial nerves, and venous plexus ${ }^{9,10}$. All classic transcranial approaches used to manage lesions of the MCF have their main limits in requiring an extensive bone removal, the disruption and possible post-operative atrophy of the temporalis muscle and a moderate-to-severe brain retraction ${ }^{10}$. In this scenario, a purely endoscopic approach such as the transorbital superior-eyelid route, may allow to expose the lateral middle cranial fossa by extradural removal of the greater and lesser sphenoid wings, followed by the dissection of the so called meningo-orbital band, with minimal disruption of normal tissue ${ }^{11,12}$. In endoscopic-assisted surgery to Meckel's cave and petrous apex, among the advantages of the transorbital approach over the endonasal patways, Lee reports the shorter access route and the possibility to perform an "interdural" dissection within the lateral wall of the cavernous sinus with a easier manipulation of tumors at their lateral and posterior borders, sparing the vidian nerve ${ }^{13}$. Literature on the topic is in steady growth with several anatomical comparative studies performed to value the feasibility of the transorbital approaches over endonasal and open patways ${ }^{14,15}$. Among published clinical series, the superior eyelid approaches to the middle skull base have been successfully used to manage spheno-orbital meningiomas (even if the en-plaque types remain a challenge) ${ }^{16}$ and neoplastic diseases such as trigeminal schwannomas ${ }^{17}$ and metastatic lesions ${ }^{10}$. Anyway, different Authors remark the limits of such approach, underlying the possibility that the unfamiliarity with the orbital anatomy may lead to orbital and globe injuries ${ }^{13,18}$. So, it must be stressed that a dogmatic approach to such complex lesions is not appropriate and the surgical expertise and confidence with the transorbital route should be properly considered before choosing the surgical access. Last but not least, the age of the patient, the possible comorbidities and the biological behaviour of the lesion must be carefully evaluated ${ }^{5,13,18}$.

The infratemporal fossa is another possible target area reachable through a superior eyelid approach, since it lies inferiorly to the middle cranial fossa floor. Its management may require the use of complex approaches, even if decisive steps forward have been made with the advent of the endonasal endoscopic tecniques ${ }^{19}$. In this respect, the orbit may represent a new potential option to reach the upper aspects of the infratemporal fossa, through both a superior or, probably better, an inferior orbital access (using the inferior orbital fissure as a natural corridor) ${ }^{20}$. It must be underlined that most of these cases, anyway, needs to be managed via a combined multiportal procedure.

Thus said, assuming that a single surgical approach might not be able to complete manage deep, multicompartimental and difficult-to-access skull base lesions, a multiportal approach, providing simultaneous entry windows, should be seriously considered ${ }^{21}$. In such cases, the superior eyelid approach may be associated with other transorbital, transnasal or even transcranial accesses, ensuring a better visualization and manipulation of the lesion from synchronous different perspectives, as well as a reduced risk of collateral damage ${ }^{18}$. If a single approach, in fact, may be insufficient to address lesions that cross neurovascular structures or are deeply located, the use of multiple accesses may allow an augmented visualization, avoiding potentially devastating complications ${ }^{21}$.

Technically speaking, the multiportal approach has its strength in the capability to perform a $360^{\circ}$ approach, for instance to the optic canal and the cavernous sinus, as well as the infratemporal fossa and selected complex cases involving the anterior and middle cranial fossa ${ }^{22}$. And more than in a single window approach, the multiportal surgery provides a multihands technique, similarly to the open approaches, taking advantages of the role of the second and third surgeons to gain an adequate exposure and visualization ${ }^{18}$.

Among surgical target, Meckel's cave and cavernous sinus pathologies seem to benefit from this kind of solution, as an alternative technique that may reduce the high morbidity traditionally associated with the other surgical accesses.

Different Authors report case report and series with the multiportal approach, represented by a combination of transorbital and transnasal routes applied in clinical settings ${ }^{21-24}$. In all cases this combination appeared safe, effective and able to take advantages of each single approach.

As a general rule regarding possible contraindications, we do feel that, whenever major vessels are totally encased by the lesion (regardless the lesion), traditional transcranial routes should be considered as first option. In such cases performing different "alternative" approaches, like multiportal endoscopic-assisted ones, should be well evaluated and balanced. Obviously, a case-by-case evaluation is mandatory by an experienced and wise multidisciplinary team.

\section{Possible alternatives}

In Table I, we schematically report the main advantages and limitations of the transorbital endoscopic approach compared to the classical open surgical approaches. 
Table I. Advantages and limitations of the superior eyelid endoscopic-assisted approach compared to the more traditional open ones.

\begin{tabular}{|c|c|c|}
\hline & Advantages & Limitations \\
\hline $\begin{array}{l}\text { Superior eyelid endoscopic-assisted } \\
\text { approach }\end{array}$ & $\begin{array}{l}\text { Short distance to the target } \\
\text { No nerve or major vessels crossing } \\
\text { Good control of the anterior pole of the temporal lobe } \\
\text { and of the medial aspect of the Sylvian fissure } \\
\text { Good access to lateral wall of the CS and Meckel's cave } \\
\text { (and petrous apex) } \\
\text { No need for brain retraction }\end{array}$ & $\begin{array}{c}\text { Difficult control of the lateral aspect of the temporal } \\
\text { fossa } \\
\text { Major vessels encasement or highly vascularized } \\
\text { lesions } \\
\text { Lesions extending too posteriorly or inferiorly }\end{array}$ \\
\hline Supraorbital approach & $\begin{array}{c}\text { Small incision } \\
\text { Good control of anterior and suprasellar/parasellar } \\
\text { regions (superior aspect) }\end{array}$ & $\begin{array}{l}\text { No control of ITF } \\
\text { No control of anterior temporal lobe region and of } \\
\text { infero-lateral aspect of CS (inferior parasellar region) }\end{array}$ \\
\hline Fronto-temporal approach & Good exposure of anterior and middle cranial base & $\begin{array}{c}\text { Need for bony work with large skin flap } \\
\text { Very difficult control of ITF } \\
\text { Necessity for management of the anterior part of the } \\
\text { temporal lobe to get the lateral wall of CS }\end{array}$ \\
\hline Pterional approach & $\begin{array}{l}\text { Good exposure of anterior and middle cranial base } \\
\text { Good exposure of sylvian fissure }\end{array}$ & $\begin{array}{l}\text { Need for bony work and large skin flap } \\
\text { Difficult control of PPS and ITF } \\
\text { Need for the management of anterior part of the } \\
\text { temporal lobe to get the lateral wall of CS }\end{array}$ \\
\hline Subtemporal approach & $\begin{array}{c}\text { Good exposure of lateral aspect of parasellar, anterior } \\
\text { pole of the temporal lobe and anterolateral posterior } \\
\text { cranial fossa }\end{array}$ & $\begin{array}{c}\text { Need for bony work with large skin flap } \\
\text { Very difficult control of PPS and ITF } \\
\text { No control of anterior cranial base } \\
\text { Need for management of anterior pole of temporal } \\
\text { lobe to obtain space for access to lateral aspect of } \\
\text { parasellar region } \\
\text { Need for major retraction to obtain suprasellar access }\end{array}$ \\
\hline FTOZ (\& variations) approach & $\begin{array}{l}\text { Wide exposure of anterior and middle cranial base } \\
\text { Good exposure of supralateral aspect of the orbit } \\
\text { Access extending to interpeduncolar and prepontine } \\
\text { cisterns }\end{array}$ & $\begin{array}{c}\text { Difficult control of PPS and ITF } \\
\text { Need for extensive bony work and large skin flap }\end{array}$ \\
\hline
\end{tabular}

CS: Cavernous Sinus; ITF: Infratemporal Fossa; PPS: Parapharyngeal Space; FTOZ: Fronto-Temporal Orbito-Zygomatich approach.

\section{Complications}

Surgical complications can be mainly divided in two groups: complications related to the surgical approach and complications related to the target regions. Obviously, the latter are independent to the chosen approach and may occur during any approaches. Another issue is the case of complications related to the approach itself. More in details, the palpebral phase can be associated to the damage to the levator palpebrae muscle, thus leading to post-operative ptosis. To avoid such complication, the use of loupes or any other magnification system can be of great help. Post-operative lid swelling may be significant. Chemosis can be present and significant. Severe injuries of the extraocular muscles, mainly the lateral rectus muscle, although really rare can be associated with post-operative diplopia. This occurs especially during drilling of the bone. A piece of silastic sheet could be useful in order to protect orbital tissues. In case of extended superior approach, a possible damage to supraorbital and suprathroclear bundles can lead to forehead numbness. Corneal abrasion and damage is a possible risk and can be pre- vented with adequate tricks. Post-operative bleeding and an eventually associated compartimental syndrome (with sight-threathning condition) are rare but possible in transorbital "corridor" surgery, requiring promt management and decompression. All these aspects should be discussed extensively with the patients, and all the possible alternatives taken into considerations.

\section{Clinical examples}

In Figure 4 we show a right spheno-orbital meningioma treated with a multiportal transnasal-transorbital endoscopic-assisted approach.

\section{Conclusions}

In conclusion, the superior eyelid endoscopic-assisted approach may be considered as a safe and promising approach to selected disease of the infratemporal, anterior and middle cranial fossa. And the multiportal approach, moreover, may overcome the limits of a single procedure, offering a multiperspective view of the spaces and the possibility to 


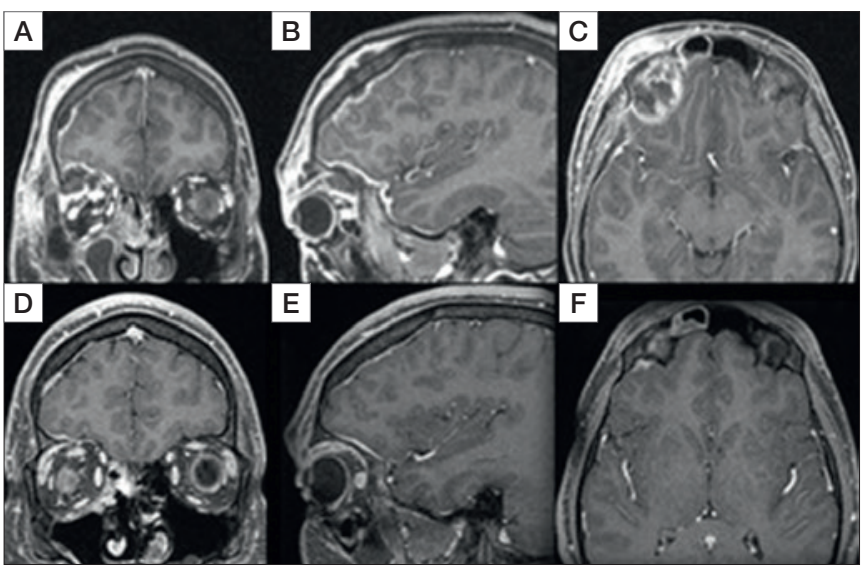

Figure 3. MRI-based evaluation of a right orbital and epidural abscess. In A, $\mathbf{B}$ and $\mathbf{C}$ the pre-operative findings. In $\mathbf{D}, \mathbf{E}$ and $\mathbf{F}$ the post-operative imaging after a superior eyelid approach to orbit and anterior cranial base.

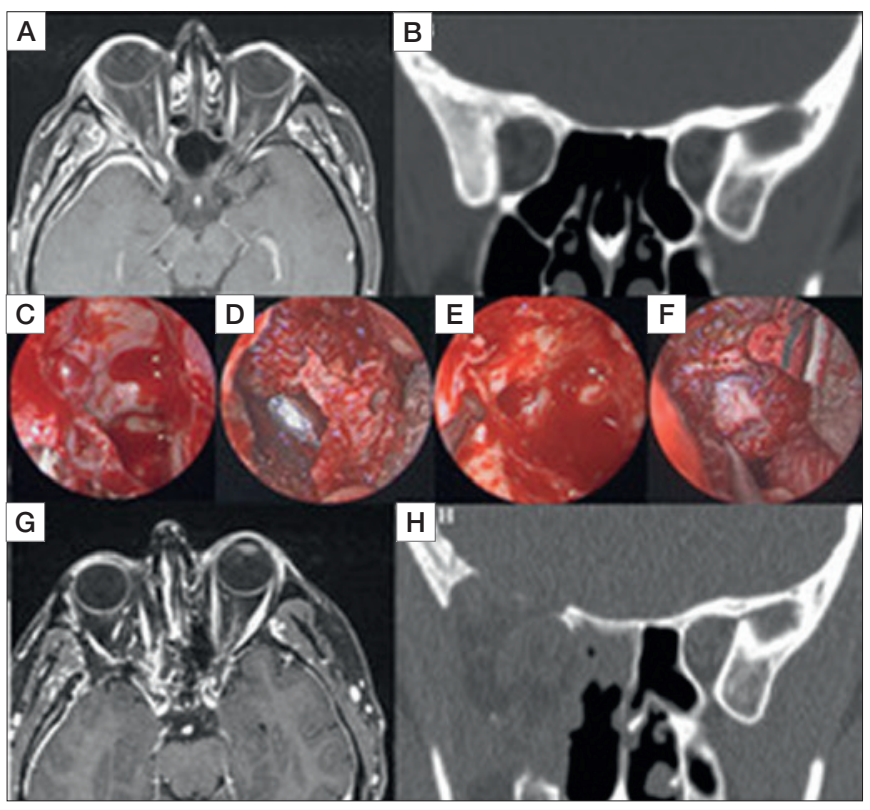

Figure 4. Multipanel figure showing the radiological pre- and post-operative imaging $(\mathbf{A}-\mathbf{B} ; \mathbf{G}-\mathbf{H})$ and the intra-operative endoscopic view $(\mathbf{C}-\mathbf{F})$ of a right spheno-orbital meningioma treated with a multiportal transnasal-transorbital endoscopic-assisted approach.

perform a $360^{\circ}$ approach to complex skull base lesions. When approaching this kind of patient a multidisciplinary evaluation and management is strongly advisable, since the merger of the different skills fits much better with the need of the patient.

Anyway, in our opinion, there is no better approach over another and the choice must always consider several elements such as the surgeon's confidence and preference, the location of the disease, the purpose of surgery.

\section{References}

Miller C, Bly R, Moe KS. Endoscopic orbital and periorbital approaches in minimally disruptive skull base surgery. J Neurol Surg B Skull Base 2020;8:459-471. https://doi.org/10.1055/s-0040-1713900

2 Moe KS, Bergeron CM, Ellenbogen RG. Transorbital neuroendoscopic surgery. Neurosurgery 2010;67:ons16-28. https://doi.org/10.1227 /01.NEU.0000373431.08464.43

Stefko ST. Combined Surgical approaches in and around the orbit. J Neurol Surg B Skull Base 2020;8:472-479. https://doi. org/10.1055/s-0040-1713938

4 Ramakrishna R, Kim LJ, Bly RA, et al. Transorbital neuroendoscopic surgery for the treatment of skull base lesions. J Clin Neurosci 2016;24:99-104. https://doi.org/10.1016/j.jocn.2015.07.021

5 Gassner HG, Schwan F, Schebesch KM. Minimally invasive surgery of the anterior skull base: transorbital approaches. GMS Curr Top Otorhinolaryngol Head Neck Surg 2016;14:Doc03. https://doi. org/10.3205/cto000118

6 Kopelovich JC, Baker MS, Potash A, et al. The hybrid lid crease approach to address lateral frontal sinus disease with orbital extension. Ann Otol Rhinol Laryngol 2014;123:826-830. https://doi. org/10.1177/0003489414538767

Lim JH, Sardesai MG, Ferreira M Jr, et al. Transorbital neuroendoscopic management of sinogenic complications involving the frontal sinus, orbit, and anterior cranial fossa. J Neurol Surg B Skull Base 2012;73:394-400. https://doi.org/10.1055/s-0032-1329617

8 Miller C, Berens A, Patel SA, et al. Transorbital approach for improved access in the management of paranasal sinus mucoceles. J Neurol Surg B Skull Base 2019;80:593-8. https://doi.org/10.1055/s-0038-1676982

9 Rychen J, Croci D, Roethlisberger M, et al. Minimally invasive alternative approaches to pterional craniotomy: a systematic review of the literature. World Neurosurg 2018;113:163-179. https://doi. org/10.1016/j.wneu.2018.02.016

10 Jeon C, Hong CK, Woo KI, et al. Endoscopic transorbital surgery for Meckel's cave and middle cranial fossa tumors: surgical technique and early results. J Neurosurg 2018 Nov 1;1-10. https://doi. org/10.3171/2018.6.JNS181099. Online ahead of print.

11 Dallan I, Di Somma A, Prats-Galino A, et al. Endoscopic transorbital route to the cavernous sinus through the meningo-orbital band: a descriptive anatomical study. J Neurosurg 2017;127:622-629. https:// doi.org/10.3171/2016.8.JNS16465

12 Di Somma A, Andaluz N, Cavallo LM, et al. Supraorbital vs endoorbital routes to the lateral skull base: a quantitative and qualitative anatomic study. Oper Neurosurg (Hagerstown) 2018;15:567-576. https://doi.org/10.1093/ons/opx256

13 Lee MH, Hong SD, Woo KI, et al. Endoscopic endonasal versus transorbital surgery for middle cranial fossa tumors: comparison of clinical outcomes based on surgical corridors. World Neurosurg 2019;122:e1491-e1504. https://doi.org/10.1016/j.wneu.2018.11.090

14 Lin BJ, Ju DT, Hsu TH, et al. Quantitative comparison of endoscopically-assisted endonasal, sublabial, and transorbital transmaxillary approaches to the anterolateral skull base. Clin Otolaryngol 2021;46:123-130. https://doi.org/10.1111/coa.13559

15 Saraceno G, Agosti E, Qiu J, et al. Quantitative anatomical comparison of anterior, anterolateral and lateral, microsurgical and endoscopic approaches to the middle cranial fossa. World Neurosurg 2020;134:e682-e730. https://doi.org/10.1016/j.wneu.2019.10.178

16 Kong DS, Kim YH, Hong CK. Optimal indications and limitations of endoscopic transorbital superior eyelid surgery for spheno-orbital meningiomas. J Neurosurg 2020 Jun 5;1-8. https://doi. org/10.3171/2020.3.JNS20297. Online ahead of print.

17 Park HH, Hong SD, Kim YH, et al. Endoscopic transorbital and en- 
donasal approach for trigeminal schwannomas: a retrospective multicenter analysis (KOSEN-005). J Neurosurg 2020;133:467-476. https://doi.org/10.3171/2019.3.JNS19492

18 Locatelli D, Pozzi F, Turri-Zanoni M, et al. Transorbital endoscopic approaches to the skull base: current concepts and future perspectives. J Neurosurg Sci 2016;60:514-525.

19 Battaglia P, Turri-Zanoni M, Dallan I, et al. Endoscopic endonasal transpterygoid transmaxillary approach to the infratemporal and upper parapharyngeal tumors. Otolaryngol Head Neck Surg 2014;150:696702. https://doi.org/10.1177/0194599813520290

20 Gerges MM, Godil SS, Younus I, et al. Endoscopic transorbital approach to the infratemporal fossa and parapharyngeal space: a cadaveric study. J Neurosurg 2019:Nov 1;1-12. https://doi. org/10.3171/2019.7.JNS191743. Online ahead of print.

${ }_{21}$ Dallan I, Castelnuovo P, Locatelli D, et al. Multiportal combined transorbital transnasal endoscopic approach for the management of selected skull base lesions: preliminary experience. World Neurosurg 2015;84:97-107. https://doi.org/10.1016/j.wneu.2015.02.034

22 Alqahtani A, Padoan G, Segnini G, et al. Transorbital transnasal endoscopic combined approach to the anterior and middle skull base: a laboratory investigation. Acta Otorhinolaryngol Ital 2015;35:173179.

23 Di Somma A, Langdon C, de Notaris M, et al. Combined and simultaneous endoscopic endonasal and transorbital surgery for a Meckel's cave schwannoma: technical nuances of a mini-invasive, multiportal approach. J Neurosurg 2020;Jul 10;1-10. https://doi. org/10.3171/2020.4.JNS20707. Online ahead of print.

24 Tham T, Costantino P, Bruni M, et al. Multiportal combined transorbital and transnasal endoscopic resection of fibrous dysplasia. J Neurol Surg Rep 2015;76:e291-e296. https://doi.org/10.1055/s-0035-1566126 